\title{
A variance-based consensus degree in group decision making problems
}

\author{
María José del Moral A. \\ Granada University \\ delmoral@ugr.es
}

\author{
Francisco Chiclana \\ De Montfort University \\ chiclana@dmu.ac.uk
}

\author{
Juan Miguel Tapia G. \\ Granada University \\ jmtaga@ugr.es
}

\author{
Enrique Herrera-Viedma \\ Granada University \\ viedma@decsai.ugr.es
}

\begin{abstract}
The variance is a well-known statistical measure and is frequently used for the calculation of variability. This concept can be used to obtain the degree of agreement in groups that have to make decisions. In this study, we propose the use of a variance derivative as an alternative for the calculation of the degree of consensus for Group Decision Making problems with fuzzy preference relations. As revealed by a subsequent comparative study, the values obtained by this new method are comparable to the values obtained by means of frequently used methods that employ distance functions and aggregation operators, while it turns out to be a simpler application method.
\end{abstract}

\section{Introduction}

In decision environments present in daily life, it is important to obtain a decision accepted by the group of people implicated. A problem of group decision making (GDM) involves a group of individuals, usually called experts, who have to choose an alternative in a set of several possible alternatives [1$3]$. In this context, is desirable an agreement among experts about the proposed alternative. The state of agreement among the members of the group is usually known by the term consensus [3-4]. In this context, consensus can be understood as a full and unanimous agreement among experts although, in most situations, that absolute agreement is not necessary. In addition, it is necessary to handle the vagueness that is present in the expression of the opinions of the experts. In this sense, new tools to represent the preferences of experts have been provided by the theory of fuzzy sets [5]. In a fuzzy context, it has become relevant to conduct the consensus session with the help of a moderator who advises people how to change their opinions until reach consensus. This way, the consensus process can be observed as an iterative process made up of several consensus rounds, in which the experts accept to change their preferences following the advice given by the moderator. The moderator knows the agreement degree in each round of the consensus process by calculating some consensus measures. This will allow him to identify whether or not an enough consensus state has been reached, that is, whether or not a consensus threshold, which may have been pre-fixed, has been reached. Several measures can be used to express different levels of consensus, among which is the one originated from the concept known as soft consensus. Several papers $[3,5-8]$ constitute the basis of many soft consensus models proposed in the literature [9-13]. Using soft consensus measures we can express different levels of agreement among experts. The use of these measures is based on the concept of similarity between preferences of the experts.

Generally, for the computation of consensus levels it is necessary to calculate and aggregate the distance measures employed to represent the proximity of the preferences of each pair of experts on each pair of alternatives [4, 9-14]. We have shown [15-17] that consensus level values are affected by the distance function and the aggregation operator used in the calculation.

Measures based on statistic variability have been used to measure agreement [18]. Most of them assess disagreement among experts by means of variance as an alternative measure of consensus. In these situations a high variance is seen as a high disagreement inside the members of the group.

In this paper we propose a new consensus measure $o$ index and perform a comparative study in the context of GDM problems with fuzzy preference relations. To do so we use the standard deviation and the coefficient of variation to calculate the consensus levels. This index could replace other consensus computations without using distance measures in iterative or noniterative processes. The implementation of this new index could allow an alternative way to measuring consensus.

We compare this proposed consensus measure with a more frequently used approach based on an aggregator and different distance functions [15-17] and acceptable results are obtained in comparison with the usual approach mentioned above. Finally, we present a ranking of these measures.

The structure of this study is the following: Section 2 introduces basic concepts about GDM problems and 
the variability elements used in this study is presented in Section 3. A comparative study is presents in Section 4. And, finally, we end this paper in Section 5 Conclusion.

\section{The GDM problem}

In a GDM problem, experts can express their preferences with several formats: preference orderings [19], utility values [11] and preference relations -fuzzy preference relations, multiplicative preference relations and linguistic preference relations- [3]. Preference relations are the representation format most used. A GDM problem with fuzzy preference relation involve a group of experts, $E=\left\{\mathrm{e}^{1}, \ldots, \mathrm{e}^{\mathrm{n}}\right\}(\mathrm{n}>1)$, who have to find the best alternative from a set of several alternatives, $X=\left\{\mathrm{x}_{1}, \ldots, \mathrm{x}_{\mathrm{m}}\right\}(\mathrm{m}>1)$, according to their preferences. Expert' preferences may be expressed through fuzzy preference relations [20-24]. A fuzzy preference relation, $\mathrm{P}$, on a finite set of alternatives $\mathrm{X}$ is characterized by a function $\mu_{P}: X \times X \rightarrow[0,1]$ which gather up the preference degree of the alternative $x_{i}$ over $\mathrm{x}_{\mathrm{j}}$ given by an expert [25]:

$$
\mu_{P}\left(x_{i}, x_{j}\right)=P\left(x_{i}, x_{j}\right)=p_{i j}
$$

being 0 the minimal preference and 1 the maximal preference. This function verifies reciprocity, i.e. $\mathrm{p}_{\mathrm{ij}}+$ $\mathrm{p}_{\mathrm{ji}}=1$, with $\mathrm{i}, \mathrm{j}$ in $\{1, \ldots, \mathrm{m}\}$ and is usually denoted by a matrix $P=\left(p_{i j}\right)$.

A fixed minimum consensus level among experts is very interesting to be obtained in order to support the decision.

The measurement of the distance between the experts' preference values facilitates the computation of the consensus level among them [26]. Some of the following distance functions are the most commonly used in its calculation [15-17, 26]:

$$
\begin{aligned}
& \text { Manhattan } d_{1}(A, B)=\sum_{i=1}^{n}\left|a_{i}-b_{i}\right| \\
& \text { Euclidean } d_{2}(A, B)=\sqrt{\sum_{i=1}^{n}\left|a_{i}-b_{i}\right|^{2}} \\
& \text { Cosine } d_{3}(A, B)=\frac{\sum_{i=1}^{n} a_{i} \cdot b_{i}}{\sqrt{\sum_{i=1}^{n} a_{i}^{2}} \sqrt{\sum_{i=1}^{n} b_{i}^{2}}}
\end{aligned}
$$

Dice $\quad d_{4}(A, B)=\frac{2 \sum_{i=1}^{n} a_{i} \cdot b_{i}}{\sum_{i=1}^{n} a_{i}^{2}+\sum_{i=1}^{n} b_{i}^{2}}$

$$
\text { Jaccard } d_{5}(A, B)=\frac{\sum_{i=1}^{n} a_{i} \cdot b_{i}}{\sum_{i=1}^{n} a_{i}^{2}+\sum_{i=1}^{n} b_{i}^{2}-\sum_{i=1}^{n} a_{i} \cdot b_{i}}
$$

where $A=\left\{a_{1}, \ldots, a_{n}\right\}$ and $B=\left\{b_{1}, \ldots, b_{n}\right\}$ are two sets of real numbers.

In order to find the similarity between preference values through the similarity function, any of these distance functions could be used by setting similarity as $\mathrm{s}=1-\mathrm{d}$ [15-17].

A similarity matrix, $\mathrm{SM}^{\mathrm{r}}=\left(\mathrm{sm}_{\mathrm{ij}}^{\mathrm{r}}\right)$ is then obtain through $\mathrm{sm}_{\mathrm{ij}}^{\mathrm{r}}=\mathrm{s}\left(\mathrm{p}_{\mathrm{ij}}^{\mathrm{r}}, \mathrm{p}_{\mathrm{ij}}\right)$. This matrix provides an evaluation of the proximity among preference values by comparing the proximity of each expert with the rest in every pair of alternatives $\left(\mathrm{x}_{\mathrm{i}}, \mathrm{x}_{\mathrm{j}}\right)$.

A consensus matrix, $\mathrm{CM}=\left(\mathrm{cm}_{\mathrm{ij}}\right)$, is then calculated by aggregating all the similarity matrices previously obtained by using an OWA operator. The aggregation operation by a quantifier guided OWA (Ordered Weighted Averaging) operator is carried out as [2728]:

$$
p_{i j}{ }^{c}=\phi_{Q}\left(p_{i j}{ }^{1}, \ldots, p_{i j}{ }^{m}\right)=\sum_{k=1}^{m} w_{k} \cdot p_{i j}{ }^{\sigma(k)}
$$

where $\sigma$ denotes a permutation function such that

$$
p_{i j}^{\sigma(k)} \geq p_{i j}^{\sigma(k+1)}, \forall k \in\{1, \ldots, n-1\}
$$

and $\mathrm{Q}$ is a fuzzy linguistic quantifier of fuzzy majority which is used to calculate the weighting vector, $\mathrm{W}=$ $\left[\mathrm{w}_{1}, \ldots, \mathrm{w}_{\mathrm{n}}\right]$.

Some operators are Maximum $(\mathrm{W}=[1,0, \ldots, 0])$, Minimum $(\mathrm{W}=[0, \ldots, 0,1])$ or Average $(\mathrm{W}=[1 / \mathrm{n}$, $1 / \mathrm{n}, \ldots, 1 / \mathrm{n}])$. Alternative representations for the concept of fuzzy majority can be found in the literature [29].

In this situation, $\mathrm{CM}=\left(\mathrm{cm}_{\mathrm{ij}}\right)$, with $\mathrm{i}, \mathrm{j}$ in $\{1, \ldots, \mathrm{m}\}$, is obtained as:

$$
c m_{i j}=\phi\left(s m_{i j}{ }^{1}, \ldots, s m_{i j}{ }^{n}\right)
$$

and it shows the consensus degree on each pair of alternatives $\left(\mathrm{x}_{\mathrm{i}}, \mathrm{x}_{\mathrm{j}}\right)$. In order to calculate the consensus degree on the relation, cr, i.e. the global agreement among all experts, an aggregation operation of all the consensus degrees at the level of pairs of alternatives is performed: 


$$
c r=\phi\left(c m_{i j}: i \neq j \& i, j=1, \ldots, m\right)
$$

In this step it is common to use an OWA operator, mainly the Average operator.

The consensus model is represented in Figure 1.

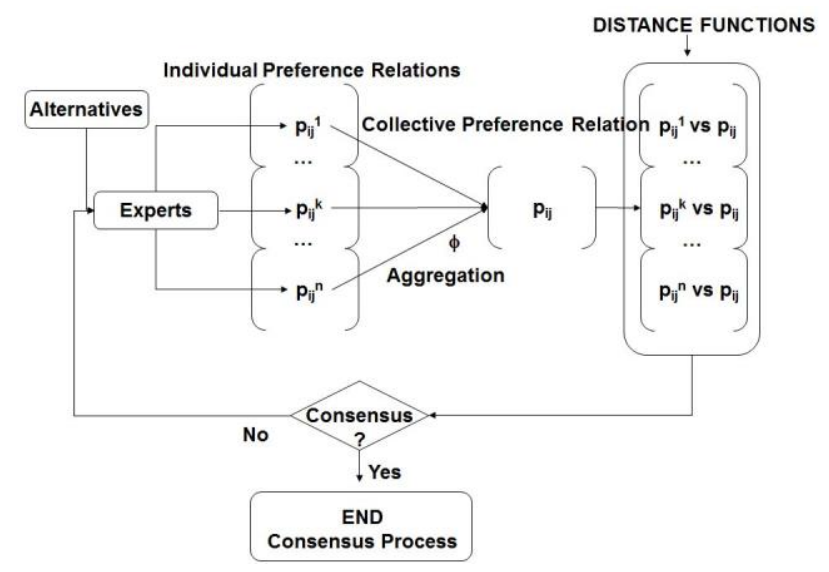

Figure 1. Consensus model with distance functions and aggregation operators.

\section{Variance based consensus index}

Among the measures of statistical dispersion [30] one of the most used is the variance. Variance measures how far a set of values are spread out from their average value. It is an important tool in data analysis [30]. Related to the variance is the standard deviation. Widely used in descriptive statistics, standard deviation shows the magnitude of the dispersion in the same units as the original data. When the purpose is to compare the homogeneity or variability among several data distributions, it is common the use of the coefficient of variation, also known as relative standard deviation. The coefficient of variation is a standardized measure of dispersion of a data distribution. It is often expressed as a percentage, and is defined as the ratio of the standard deviation to the mean or its absolute value.

In this paper the aforementioned dispersion measures are introduced in the framework of a GDM problem with fuzzy preference relations in the following way.

\section{Definition (Variance on a pair of alternatives $\left(x_{i}, x_{j}\right)$ with fuzzy preferences)}

Let $\left\{p_{i j}{ }^{1}, \ldots, p_{i j}{ }^{n}\right\}$ be the preferences of $n$ experts on a pair of alternatives $\left(\mathrm{x}_{\mathrm{i}}, \mathrm{x}_{\mathrm{j}}\right)$ with $\mathrm{i}, \mathrm{j}$ in $\{1, \ldots, \mathrm{m}\}$. The variance for a pair of alternatives $\left(\mathrm{x}_{\mathrm{i}}, \mathrm{x}_{\mathrm{j}}\right)$ is defined as

$$
V A R_{i j}=\frac{1}{n} \sum_{k=1}^{n}\left(p_{i j}{ }^{k}-\bar{p}_{i j}\right)^{2}
$$

with $\bar{p}_{i j}=\frac{1}{n} \sum_{k=1}^{n} p_{i j}{ }^{k}$ is the average value.

\section{Property 1 (Variance properties)}

i) $0 \leq V A R_{i j}$

$$
\text { ii) } \quad V A R_{i j}=V A R_{j i} \quad \forall i, j \in\{1, \ldots, m\}
$$

This measure of variability in GDM problems with fuzzy preference relations can be understood as a measure of dispersion: the greater the value of the dispersion measure, the greater the variability and vice versa, the lower the dispersion value, the greater the homogeneity.

Definition (Standard deviation on a pair of alternatives $\left(x_{i}, x_{j}\right)$ with fuzzy preferences)

Let $\left\{p_{i j}{ }^{1}, \ldots, p_{i j}{ }^{n}\right\}$ be the preferences of $n$ experts on a pair of alternatives $\left(\mathrm{x}_{\mathrm{i}}, \mathrm{x}_{\mathrm{j}}\right)$ with $\mathrm{i}, \mathrm{j}$ in $\{1, \ldots, \mathrm{m}\}$. The standard deviation for a pair of alternatives $\left(\mathrm{x}_{\mathrm{i}}, \mathrm{x}_{\mathrm{j}}\right)$ is defined as

$$
S D_{i j}=+\sqrt{V A R_{i j}}=+\sqrt{\frac{1}{n} \sum_{k=1}^{n}\left(p_{i j}{ }^{k}-\bar{p}_{i j}\right)^{2}} \quad i, j \in\{1, \ldots, m\}
$$

\section{Property 2 (Standard deviation properties)}

i) $0 \leq S D_{i j}$

$$
\text { ii) } S D_{i j}=S D_{j i} \quad \forall i, j \in\{1, \ldots, m\}
$$

Two opposite situations can be observed in what dispersion goes: null dispersion -minimum variabilityand total dispersion -maximum variability-. In the first case, minimum variability, all $\mathrm{p}_{\mathrm{ij}}{ }^{\mathrm{k}}$ take the same value:

$p_{i j}{ }^{1}={p_{i j}}^{2}=\ldots={p_{i j}}{ }^{n-1}={p_{i j}}{ }^{n}$

In the second case, maximum variability, only one value is different from zero:

$$
p_{i j}{ }^{1}=p_{i j}{ }^{2}=\ldots=p_{i j}{ }^{n-1}=0 \quad \& \quad p_{i j}{ }^{n} \neq 0
$$


Property 3 (Standard deviation bounded)

$$
0 \leq S D_{i j} \leq \bar{p}_{i j} \sqrt{n-1} \quad \forall i, j \in\{1, \ldots, m\}
$$

At this point we introduce a new consensus measure as following.

Definition (Standard deviation consensus index on a pair of alternatives $\left(x_{i}, x_{j}\right)$ with fuzzy preferences)

Let $\left\{\mathrm{p}_{\mathrm{ij}}{ }^{1}, \ldots, \mathrm{p}_{\mathrm{ij}}{ }^{\mathrm{n}}\right\}$ be the preferences of $\mathrm{n}$ experts on $\mathrm{a}$ pair of alternatives $\left(\mathrm{x}_{\mathrm{i}}, \mathrm{x}_{\mathrm{j}}\right)$ with $\mathrm{i}, \mathrm{j}$ in $\{1, \ldots, \mathrm{m}\}$. The standard deviation consensus index for a pair of alternatives $\left(\mathrm{x}_{\mathrm{i}}, \mathrm{x}_{\mathrm{j}}\right)$ is defined as

$S D C_{i j}=1-\frac{1}{\bar{p}_{i j} \sqrt{n-1}} \cdot S D_{i j} \quad \forall i, j \in\{1, \ldots, m\}$

Standard deviation consensus index can be displayed as a matrix:

$$
S D C=\left(S D C_{i j}, \quad i, j=1, \ldots, m\right)
$$

\section{Property 4 (Bounded values)}

$$
0 \leq S D C_{i j} \leq 1 \quad \forall i, j \in\{1, \ldots, m\}
$$

\section{Property 5 (Reciprocity)}

$$
S D C_{i j}=S D C_{j i} \quad \forall i, j \in\{1, \ldots, m\}
$$

Definition (Standard deviation consensus index on the relation)

The standard deviation consensus index on the relation is defined as:

$$
C_{S D C}=\frac{\sum_{i=1}^{m} \sum_{j>i}^{m} S D C_{i j}}{\sum_{k=1}^{m-1}(m-k)}
$$

Definition (Coefficient of variation on a pair of alternatives $\left(x_{i}, x_{j}\right)$ with fuzzy preferences)

Let $\left\{\mathrm{p}_{\mathrm{ij}}{ }^{1}, \ldots, \mathrm{p}_{\mathrm{ij}}{ }^{\mathrm{n}}\right\}$ be the preferences of $\mathrm{n}$ experts on a pair of alternatives $\left(x_{i}, x_{j}\right)$ with $i, j$ in $\{1, \ldots, m\}$. The coefficient of variation consensus index for a pair of alternatives $\left(\mathrm{x}_{\mathrm{i}}, \mathrm{x}_{\mathrm{j}}\right)$ is defined as
$C V_{i j}=\frac{S D_{i j}}{\left|\bar{p}_{i j}\right|} \quad \forall i, j \in\{1, \ldots, m\}$

\section{Property 6 (Coefficient of variation bounded)}

$$
0 \leq C V_{i j} \leq \sqrt{n-1} \quad \forall i, j \in\{1, \ldots, m\}
$$

Then we can define a new consensus index as follows.

Definition (Coefficient of variation consensus index on a pair of alternatives $\left(x_{i}, x_{j}\right)$ with fuzzy preferences)

Let $\left\{p_{i j}{ }^{1}, \ldots, p_{i j}{ }^{n}\right\}$ be the preferences of $n$ experts on a pair of alternatives $\left(\mathrm{x}_{\mathrm{i}}, \mathrm{x}_{\mathrm{j}}\right)$ with $\mathrm{i}, \mathrm{j}$ in $\{1, \ldots, \mathrm{m}\}$. The coefficient of variation consensus index for a pair of alternatives $\left(\mathrm{x}_{\mathrm{i}}, \mathrm{x}_{\mathrm{j}}\right)$ is defined as

$$
C V C_{i j}=1-\frac{1}{\sqrt{n-1}} \cdot C V_{i j} \quad \forall i, j \in\{1, \ldots, m\}
$$

Property 7 (Identity)

$$
S D C_{i j}=C V C_{j i} \quad \forall i, j \in\{1, \ldots, m\}
$$

The consensus model is represented in Figure 2.

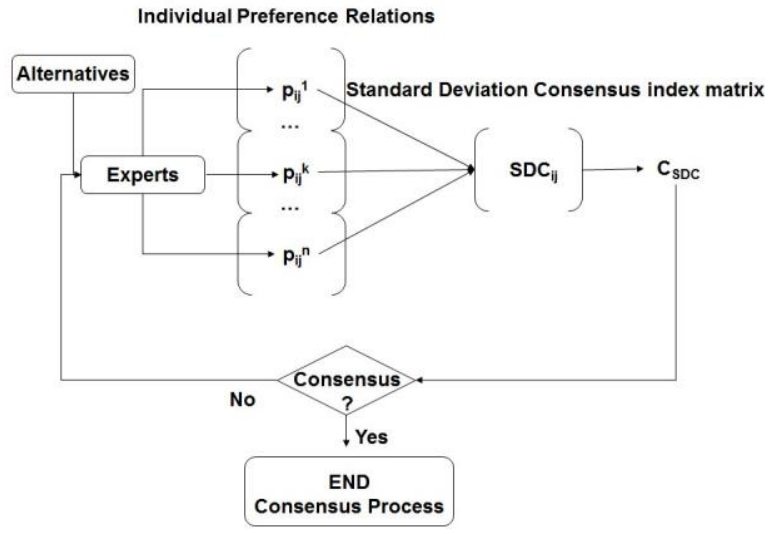

Figure 2. Consensus model with proposed consensus index

As can be seen, Figure 1 is more complex than Figure 2. So, our proposal is an easier consensus index. 


\section{A comparative study. Experimental design and results}

In this paper, we develop a strategy already used in previous documents [15-17] consisting in contrasting a statistical hypothesis through a non-parametric hypothesis test. The hypothesis to be tested is stated as follows:

$H_{0}$ : The application of $S D C / C V C$ as a consensus measure in GDM problems with fuzzy preference relations do not produce significant differences versus the use of a distance $\left(d_{i}\right)$ with an Average OWA for this measurement.

A total of 50 random GDM problems were generated for 4 alternatives and 3 experts. The OWA operator used was Average, being the weighting vector $\mathrm{w}=[1 / 3,1 / 3,1 / 3]$, and the distance functions the ones given in Section 2.2. We used the nonparametric Wilcoxon signed-ranks test to test the new hypothesis. The results are showed in Table 1.

Table 1. P-values obtained for Wilcoxon

\begin{tabular}{llllll}
\multicolumn{7}{c}{ tests } \\
\hline Measures & $\begin{array}{l}S D C \\
\text { vs } d_{1}\end{array}$ & $\begin{array}{l}S D C \\
\text { vs } d_{2}\end{array}$ & $\begin{array}{l}S D C \\
\text { vs } d_{3}\end{array}$ & $\begin{array}{l}S D C \\
\text { vs } d_{4}\end{array}$ & $\begin{array}{l}S D C \\
\text { vs } d_{5}\end{array}$ \\
\hline P-value & & & & & \\
& 0.000 & 0.000 & 0.023 & 0.037 & 0.000 \\
\hline
\end{tabular}

It can be observed that $S D C$ is significantly different (at $\alpha=0.05$ ) when it is compared with $d_{1}, d_{2}$, $d_{3}, d_{4}$ and $d_{5}$. So, there are significant differences were found among the five distance functions proposed in this study by using test.

Table 2, depicted in figure 3 , shows the level of consensus (in percentage) achieved in the different cases analyzed. The higher the value of the consensus degrees, the higher the global degree of consensus. The results show the relative position of the proposed $S D C$ index facing distance functions usually used, and also shown that this index could be used as a measurement of consensus degree in GDM problems.

Table 2. Consensus degrees in percentages

\begin{tabular}{llllllc}
\hline Measures & $d_{1}$ & $d_{2}$ & $d_{3}$ & $d_{4}$ & $d_{5}$ & $S D C$ \\
\hline Percentage & 60 & 60 & 100 & 100 & 80 & 96
\end{tabular}

Figure 3, shows the level of consensus (in percentage) achieved by SDC is very similar to Cosine and Dice distance cases analysed.

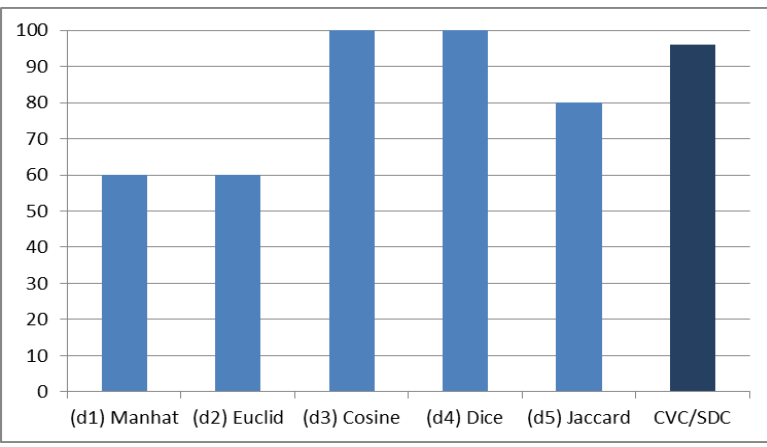

Figure 3. Consensus degree in percentages

Figure 4 displays the differences among the considered measures $\left(d_{1}, d_{2}, d_{3}, d_{4}, d_{5}, S D C\right)$ through an ideal simulation that shows the number of rounds necessary to reach an acceptable consensus degree value previously fixed.

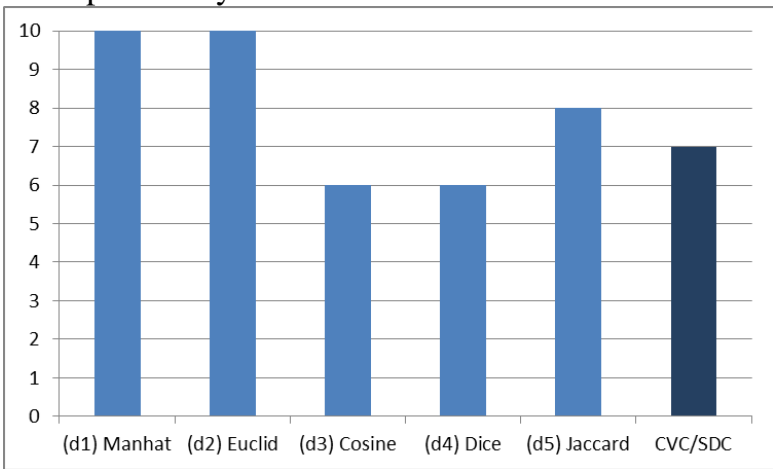

Figure 4. Number of consensus rounds (Minimum fixed in 6)

Based on the previous analysis we can draw some rules to speed up or slow down the convergence of the consensus that could prove a useful decision support tool in GDM problem.

i. The SDC value helps the consensus process to convergence faster than the Manhattan $\left(\mathrm{d}_{1}\right)$ and the Euclidean $\left(\mathrm{d}_{2}\right)$ distance functions.

ii. The SDC value helps the consensus process to converge lightly slower than the Cosine $\left(\mathrm{d}_{3}\right)$ and the Dice $\left(\mathrm{d}_{4}\right)$ distance functions.

iii. The SDC value helps the consensus process to converge lightly faster that the Jaccard $\left(\mathrm{d}_{5}\right)$ distance function.

It seems reasonable that these rules allow using the proposed consensus index to speed up or slow down the consensus process. So, SDC provides results similar to those of the other models considered in this study. 


\section{Conclusion}

We have proposed a new consensus index based on the study of the variability of data by standard deviation. We have compared this new index with five well-known distance functions, being considered as an aggregator operator one frequently used, the average operator.

Outcomes of the experiment show acceptable results regarding the consensus behavior of the proposed index, similar to those derived from the considered distances functions. In addition, we have established a ranking of these different measures of the level of consensus in GDM problems with diffuse preference relations.

\section{Acknowledgements}

The authors would like to acknowledge FEDER financial support from the Project TIN2016-75850-R.

\section{References}

[1] S.J. Chen, C.L. Hwang, Fuzzy Multiple Attribute Decision-Making: Methods and Applications, Springer Verlag, New York, 1992.

[2] J.C. Fodor, M. Roubens, Fuzzy Preference Modelling and Multicriteria Decision Support, Kluwer Academic Publishers, 1994.

[3] E. Herrera-Viedma, F.J. Cabrerizo , J. Kacprzyk and W. Pedrycz, "A review of soft consensus models in a fuzzy environment", Information Fusion, 2014, 17, pp. 4-13.

[4] F.J. Cabrerizo, J.M. Moreno, I.J. Perez and E. HerreraViedma, "Analyzing consensus approaches in fuzzy group decision making: advantages and drawbacks", Soft Computing, 2010, 14(5), pp. 451-463.

[5] L.A. Zadeh, "Fuzzy sets", Information and Control, 1965, 8 (3), pp. 338-353.

[6] J.Kacprzyk and M. Fedrizzi, "Soft consensus measures for monitoring real consensus reaching processes under fuzzy preferences", Control and Cybernetics, 1986, 15, pp. 309323.

[7] J.Kacprzyk and M. Fedrizzi, "A "soft" measure of consensus in the setting of partial (fuzzy) preferences", European Journal of Operational Reseach, 1988, 34(3), pp. 316-325.

[8] J.Kacprzyk and M. Fedrizzi, "A "human-consistent" degree of consensus based on fuzzy logic with linguistic quantifiers", 1989, 18(3), pp. 275-290.
[9] F. Herrera, E. Herrera-Viedma, J.L. Verdegay, "A model of consensus in group decision making under linguistic assessments", Fuzzy Sets and Systems, 1996, 78 (1), pp. 7387.

[10] F. Herrera, E. Herrera-Viedma, J.L. Verdegay, "A rational consensus model in group decision making using linguistic assessments", Fuzzy Sets and Systems, 1997, 88 (1), pp. 31-49.

[11] E. Herrera-Viedma, F. Herrera, F. Chiclana, "A consensus model for multiperson decision making with different preference structures", IEEE Transactions on Systems Man and Cybernetics-Part A: Systems and Humans, 2002, 32(3), pp. 394-402.

[12] E. Herrera-Viedma, L. Martinez, F. Mata, F. Chiclana, "A consensus support system model for group decisionmaking problems with multigranular linguistic preference relations", IEEE Transactions on Fuzzy Systems, 2005, 13(5), pp. 644-658.

[13] E. Herrera-Viedma, S. Alonso, F. Chiclana, and F. Herrera, "A consensus model for group decision making with incomplete fuzzy preference relations", IEEE Transactions on Fuzzy Systems, 2007, 15(5), pp. 863-877.

[14] I.J. Perez, F.J. Cabrerizo, S. Alonso and E. HerreraViedma, "A new consensus model for group decision making problems with non homogeneous experts", IEEE Transactions on Systems, Man, and Cybernetics: Systems, 2014, 44(4), pp. 494-498.

[15] F. Chiclana, J. M. Tapia, M. J. Del Moral, E. HerreraViedma, "A statistical comparative study of different similarity measures of consensus in group decision making", Information Sciences, 2013, 221, pp. 110-123.

[16] M.J. del Moral, F. Chiclana, J.M. Tapia, and E. HerreraViedma, "A Comparative Study on Consensus Measures in Group Decision Making", International Journal of Intelligent Systems, 2018, 33 (8), pp. 1624-1638.

[17] M. J. del Moral, J. M. Tapia, F. Chiclana, A. Al-Hmouz, E. Herrera-Viedma, "An analysis of consensus approaches based on different concepts of coincidence", Journal of Intelligent and Fuzzy Systems, 2018, 34 (4), pp. 2247-2259.

[18] Y. Akiyama, J. Nolan, M. Darrah, M.A. Rahem and L. Wang, "A method for measuring consensus within groups: An index of disagreement via conditional probability", Information Sciences, 2016, 345, pp. 116-128.

[19] T. Tanino, "Fuzzy preference orderings in group decision making", Fuzzy Sets and Systems, 1984, 12 (2), pp. $117-131$

[20] I. Millet, "The effectiveness of alternative preference elicitation methods in the analytic hi-erarchy process", Journal of Multi-Criteria Decision Analysis, 1997, 6 (1), pp. 41-51. 
[21] J. Kacprzyk, "Group decision making with a fuzzy linguistic majority”, Fuzzy Sets and Systems, 1986, 18 (2), pp. 105-118.

[22] F. Chiclana, F. Herrera and E. Herrera-Viedma, "Integrating three representation models in fuzzy multipurpose decision making based on fuzzy preference relations", Fuzzy Sets and Systems, 1998. 97 (1), pp. 33-48.

[23] F. Chiclana, F. Herrera and E. Herrera-Viedma, "A note on the internal consistency of various preference representations", Fuzzy Sets and Systems, 2002, 131 (1), pp. 75-78.

[24] E. Herrera-Viedma, F. Chiclana, F. Herrera and S. Alonso, "Group decision-making model with incomplete fuzzy preference relations based on aditive consistency", IEEE Transactions on Systems, Man and Cybernetics, Part B, Cybernetics, 2007, 33(1), pp. 176-189.

[25] W. Pedrycz, R. Parreiras and P. Ekel, Fuzzy Multicriteria Decision-Making. Models, Methods and Applications. Chichester, John Wiley \& Sons, 2011.
[26] M.M. Deza and E. Deza, Encyclopedia of Distances. Berlin Heidelberg, Springer, 2009.

[27] L.A. Zadeh, "A computational approach to fuzzy quantifiers in natural languages", Computers \& Mathematics with Applications, 1983, 9 (1), pp. 149-184.

[28] R.R. Yager, "On ordered weighted averaging aggregation operators in multicriteria decision making", IEEE Transactions on Systems, Man and Cybernetics 1988, 18 (1), pp. 183-190.

[29] F. Chiclana, E. Herrera-Viedma, F. Herrera and S. Alonso, "Some induced ordered weighted averaging operators and their use for solving group decision making problems based on fuzzy preference relations", European Journal of Operational Research, 2007, 182 (1), pp. 383-399.

[30] G.C. Canavos, Applied Probability and Statistical Methods. Boston New York, Little, Brown and Company, 1984. 